
$\$$ Research Square
Preprints are preliminary reports that have not undergone peer review.
They should not be considered conclusive, used to inform clinical practice, or referenced by the media as validated information.

\title{
The Combinatory Effects of Zinc Oxide Nanoparticles (ZnO NPs) and Thiamine on Skin of Alloxan-Induced Diabetic Mice; A Stereological and Biochemical Study
}

\section{Rahmat Allah Fatahian dehkordi ( $\square$ fatahian_1349@yahoo.com )}

Shahrekord University Faculty of Veterinary Medicine https://orcid.org/0000-0003-2126-6847

\section{Pasalar Sekineh}

Shahrekord University Faculty of Veterinary Medicine

\section{Saied Habibian Dehkordi}

Shahrekord University Faculty of Veterinary Medicine

Bahnaz Karimi

Shahrekord University Faculty of Veterinary Medicine

\section{Research Article}

Keywords: Diabetes, ZnO NPs, Thiamine, Skin, Mice

Posted Date: January 17th, 2022

DOI: https://doi.org/10.21203/rs.3.rs-1228507/v1

License: (c) (i) This work is licensed under a Creative Commons Attribution 4.0 International License.

Read Full License 


\section{Abstract}

Various studies have shown that ZnO NPs as an anti-diabetic agent can be effective in the experimental model of diabetes. This study aimed to investigate treatment effects of ZnO NPs plus thiamine on histostereological and biochemical parameters in the diabetic mouse skin. In total 49 BALB/C mice were used and divided into seven groups. Fourteen mice were equally considered as the control and thiamine groups (groups I and II). The rest of the mice were injected with alloxan $(220 \mathrm{mg} / \mathrm{kg})$ to induce diabetes; one untreated diabetes group (group III). Other diabetic mice were treated with ZnO NPs $(0.1$ and $0.5 \mathrm{mg} / \mathrm{kg}$ ) alone (groups IV and V, respectively) and along with thiamine (groups VI and VII, respectively). Body weights of mice at days 0,10 , and 20 were calculated to appraise weight gain. Stereological and biochemical parameters were measured to evaluate diabetes effects in all groups. An increase in weight was observed in the diabetic group compared to the control group. Diabetic skin showed decreasing in volume density of collagen bundles and decreasing in the epidermis and dermis thickness, as well as an increase in the hypodermis's thickness. Administration of ZnO NPs ( 0.1 and $0.5 \mathrm{mg} / \mathrm{kg})$ alone and along with thiamine in the diabetic animals resulted in anti-hyperglycemic activity, reducing GGT, BUN, Cr, MDA, and NO levels in treated diabetic mice. In conclusion, the concomitant use of ZnO NPs along with thiamine presents the potential as a combination therapy for the treatment of alloxan-induced diabetic mice skin changes.

\section{Introduction}

Diabetes is a chronic metabolic disease in which some disturbances occur in the metabolism of lipids, proteins and carbohydrates, besides an increase in blood glucose level [1, 2]. Complications followed by this disease include nephropathy, retinopathy and neuropathy. It can trigger cardiovascular disorders like cardiac infarction and hypertension and also cataract in the eyes [3]. Since some researchers have found changes in the skin epidermis in diabetic patients, so this has led to increased attention to the study of non-injured diabetic skin [4]. Skin diseases caused by diabetes have serious side effects; therefore, recognizing the most effective treatment measures results from a better understanding of the pathology of diabetic skin disorders [5]. Although several factors may be involved in chronic skin complications in diabetics, these side effects become more complicated because of changes in the skin's structure. Besides, fibroblast growth failure decreased collagen synthesis, and, in particular, accumulation of advanced glycation end products (AGEs) occurs in diabetic skin complications [6].

In recent years, many studies have been conducted on zinc oxide $(\mathrm{ZnO})$ and various forms of its nanostructures. It has also a vast application in sensors due to its high sensitivity to chemicals and high contact surface. ZnO NPs trap light due to their high contact surface [7], therefore, these nanoparticles are frequently used in the manufacture of solar cells. Other applications of these compounds are iron galvanization [8], pigments, corrosion preventing agents, production of toothpaste, sunscreens, etc. [9]. ZnO NPs have antibacterial and antifungal properties that are used in prophylactic drugs against bacterial disease [10]. ZnO NPs, as a new agent for zinc delivery, in addition to its biotechnological applications, have many implications for the treatment of numerous diseases, including diabetes[11]. 
The first vitamin discovered in the group of B vitamins was thiamine (B1). In the human body, this vitamin is converted to free thiamine and phosphorylated to different forms, including mono-, di-, tri- and Pyrophosphate forms, which is the active form of thiamine [12]. One of the most important co-factors in many crucial metabolic processes, including the production of acetylsalicylic acid (COA), Calvin cycle and Pentose phosphate pathway, is thiamine pyrophosphate [13]. In the body, high concentrations of thiamine are found in skeletal muscle, heart, liver, kidney and brain (Martin 2001). The most important functions of thiamine are carbohydrate catabolism and nucleic acid and NADPH production [14]. most important functions of thiamine are carbohydrate catabolism and nucleic acid and NADPH production [15]. It has been also shown that thiamine can stabilize the membrane ion channels and change their activity [16]. The application of thiamine in the treatment of neurological disorders and seizures has been revealed and proven for healing of diabetic complications. Studies on laboratory animals showed that there is a logical relationship between thiamine and pre-synaptic acetylcholine release [17].

The present study aimed to evaluate the preventive effects of two different concentrations from ZnO NPs ( 0.1 and 0.5 ) alone and along with thiamine against diabetes-induced skin changes in a mouse model.

\section{Materials And Methods}

\section{Animals}

In this experimental study, 49 healthy male BALB/C mice, weighing about $22 \pm 1 \mathrm{~g}$ and 5-weeks-old (each group 8 samples) were selected. As an adaptation period, animals were kept for a week at a temperature of $19 \pm 2^{\circ} \mathrm{C}$ with a 12 -hour dark-light cycle. In order to provide a convenient environment during the experiment period, cage floors were covered with fresh and soft sawdust, and every three days the cages were cleansed to maintain the hygiene. The animals were prepared with commercial mouse pellet food containing essential vitamins required for the body besides free access to water. The commercial mouse pellet diet was purchased from Experimental Animal Center in Tehran, Iran. All ethical regulations and protocols on laboratory animal's research were considered and approved by the Animal Rights Committee of the Shahrekord Veterinary Faculty.

\section{Preparation of ZnO Nanoparticles}

ZnO nanoparticles gained from US Research Nanomaterials, Inc., (Houston, TX, 77084, USA). This nanoparticle $(\mathrm{ZnO})$ harvest itself was a white powder with amount of purity $\geq 99+\%$. The actual characteristics of $\mathrm{ZnO}$ nanoparticles refer to its basic physical properties. Nanoparticles of $\mathrm{ZnO}$ had dimensions of 10-30 nm in size (average $20 \mathrm{~nm}$ ), as listed in Table 1, and used in concentrations of 0.1 and $0.5 \mathrm{mg} / \mathrm{kg}$ (figure 1) [2].

\section{Grouping and Sampling}

After a week of adaptation to the laboratory environment, the mice were randomly divided into 7 groups of 7 individuals each. The diabetes was induced in the experimental mice (groups 3 to 7 ) by using a 
single intraperitoneal injection (IP) at a dose of $220 \mathrm{mg} / \mathrm{kg}$ body weight of alloxan monohydrate (SigmaAldrich, St. Louis, MO, USA) in PBS soluble ( $\mathrm{pH}=7)$. Seventy-two hours later, a few mice were randomly selected from diabetic mice and their fasting blood glucose was measured. Mice with a blood glucose level of above $200 \mathrm{mg} / \mathrm{dl}$ [2] were considered diabetic mice. Also, the effects of diabetes were assessed by biopsy of the pancreas with the approval of a pathologist in some induced diabetes specimens as definitive confirmation.

With diabetes confirmed, $\mathrm{ZnO}$ nanoparticles were injected into the diabetic mice at two doses of 0.1 and $0.5 \mathrm{mg} / \mathrm{kg}$ [2] and thiamine injected at a dose of $5 \mathrm{mg} / 100 \mathrm{~g}$. Finally, all mice were divided into the following groups: All the injections were intraperitoneal (IP).

group I: Control group; distilled water administered.

group II: Thiamine (5 mg/100 g)

group III: Diabetic group (injection of alloxan; $220 \mathrm{mg} / \mathrm{kg}$ )

group IV: Diabetes + ZnO nanoparticles $0.1 \mathrm{mg} / \mathrm{kg}$

group V: Diabetes + ZnO nanoparticles $0.5 \mathrm{mg} / \mathrm{kg}$

group Vl: Diabetes + ZnO nanoparticles $0.1 \mathrm{mg} / \mathrm{kg}$ along with thiamine $(5 \mathrm{mg} / 100 \mathrm{~g})$

group VII: Diabetes + ZnO nanoparticles $0.5 \mathrm{mg} / \mathrm{kg}$ along with thiamine $(5 \mathrm{mg} / 100 \mathrm{~g}$ )

On the 20th day after the last injection, the mice were anesthetized (with fasting) by chloroform (Merck KGaA, Index No: 2806-18-9), and the blood samples were withdrawn directly from the ventricle of the heart. Blood was centrifuged (Hetich-Germany) for $10 \mathrm{~min}$ at $3000 \mathrm{r} / \mathrm{min}$ and $4 \mathrm{oC}$, the supernatant solution was reserve at $-70 \mathrm{oC}$ until biochemical analysis.

The skin samples at the three areas mid-dorsal, mid-ventral and lateral were considered. After shaving the long hair, the skin from the mentioned regions was excised and trimmed into small-size pieces, fixed in a $10 \%$ buffered formalin (Merck) solution for histo-morphometric examinations. Tissue sections of about $5 \mu \mathrm{m}$ were serially obtained, stained with $\mathrm{H} \& \mathrm{E}$ and ...., and evaluated under the light microscope.

\section{Stereological evaluation}

According to the table of random numbers, in the interval between the 50 sections the first section, or primary section (e.g., $10^{\text {th }}$ section), and the second section that is reference section were selected. Sampling in the distance between sections was so that each 50th section was sampled (the primary sections). Therefore, for the primary and reference sections, e.g. 10, 12, 60, 62 were sampled in the entire skin; as detailed in our previous research (figure 1) [18]. 
To evaluate the volume densities of tissue collagen bundles and fibroblast, a network of uniformly and permanently spaced points (point grid) was superimposed at random over the image of each predicted section. Collagen bundles that were hit by a point were sampled and subjected to volume densities estimation according to the number of points that hitting with the bundles. The total volume of collagen and fibroblasts were calculated using the following formula [19]:

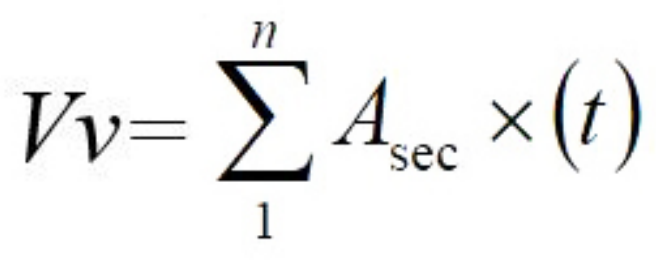

Where, $A_{s e c}$ is the area of cut surfaces $\left(1^{\text {st }}-n^{\text {th }}\right.$ slice) of systematic-random sections through the structure, and $t$, the thickness of the sections.

\section{Measurement of serum glucose}

Serum glucose levels were measured using a glucose analysis kit (Pars Azmoon Co, Tehran, Iran). The principle was based on the bi-enzymatic assay comprise enzymatic oxidation of glucose to gluconic acid, yielding hydrogen peroxide and then the reaction of hydrogen peroxide with 4-aminoantipyrine and phenol to yield the colorimetric product which is measured at $500 \mathrm{~nm}$. The results were reported as $\mathrm{mg} / \mathrm{dl}$.

\section{Estimation of MDA Level}

Malondialdehyde (MDA) as the end product of lipid peroxidation reacts with Thiobarbituric acid (TBA) and yields colored complex which can be measured spectrophotometrically [20]. In this study, $2 \mathrm{ml}$ of TBA reagent containing $0.375 \%$ TBA, $15 \% \mathrm{TCA}$ and $0.25 \mathrm{~mol} / \mathrm{L} \mathrm{HCl}$ was added to $1 \mathrm{ml}$ of serum from all groups. The mixture was placed in boiling water for $50 \mathrm{~min}$, cooled to room temperature and centrifuged at $1000 \mathrm{rpm}$ for $10 \mathrm{~min}$. Thereafter, the absorbance of the supernatant was read at the wavelength of 535 $\mathrm{nm}$ against the blank reference. The results were calculated by using a molar extinction coefficient for MDA of $1.56 \times 10^{5} / \mathrm{M} / \mathrm{cm}$. The concentration of MDA was expressed as $\mathrm{nmol} / \mathrm{ml}$ [21].

\section{Nitric oxide assay}

Briefly, $1 \mathrm{ml}$ of serum was deproteinized by adding ten microliters of $1.5 \mathrm{~g} / \mathrm{mL} \mathrm{ZnSO4}$ solution. The mixture was vortexed and centrifuged at $10000 \times \mathrm{g}$ for $10 \mathrm{~min}$ at $4{ }^{\circ} \mathrm{C}$. Then, $100 \mathrm{ul}$ of the supernatant was added to a 96-well ELISA plate, and each well was submitted to $100 \mu \mathrm{L}$ of vanadium (III) chloride $(8 \mathrm{mg} / \mathrm{ml})$ which converts nitrate to nitrite. After the addition of $100 \mathrm{ul}$ of Griess reagent (equal mixture of $1 \%$ sulphanilamide in $5 \%$ phosphoric acid and $0.1 \% \mathrm{~N}$-(1-naphthyl) ethylenediamine hydrochloride in distilled water), the plates were maintained at room temperatures for 30 minutes and the nitrite production was quantified calorimetrically at $540 \mathrm{~nm}$. The NO levels were calculated using various concentrations of sodium nitrite $(0.1-100 \mu \mathrm{m})$ as a standard and expressed as $\mu \mathrm{mol} / \mathrm{ml}$ [22]. 
Serum BUN was measured using a commercial kit (Pars Azmoon Co., Tehran, Iran) based on the enzymatic hydrolysis of urea to ammonia by urease. Then, in a parallel reaction, the ammonia is converted to glutamate by glutamate dehydrogenase and this reaction was monitored at $340 \mathrm{~nm}$. The $\mathrm{Cr}$ level was measured by the Jaffe method (Pars. Azmoon Kit, Tehran, Iran) in which creatinine reacts with picric acid to form a reddish complex [23].

\section{GGT assay}

Gamma-glutamyl transferase (GGT) activity was measured by using the Pars Azmoon kit (Tehran, Iran, according to the manufacturer). The reaction is evaluated based on transferring of $\gamma$-glutamyl group from Y-glutamyl-p-nitroanilide to acceptor glycylglycine and production of para-nitroaniline which can be determined calorimetrically at $405 \mathrm{~nm}$; the results were reported as $\mathrm{U} / \mathrm{I}$.

\section{Statistical Analysis}

Statistical analyses of volume, histo-morphometric and biochemical data were carried out using the SPSS statistical software package version 23.0 (SPSS Inc., Chicago, IL) for Windows. Data are declared as mean \pm standard deviation (SD) and statistical variations were tested by One-way ANOVA. LSD posthoc test was applied and the values confirming $p<0.05$ were considered significant compared to the rest.

\section{Results}

\section{Body weight}

There were no deaths during and after investigating due to drug injection.

To assess the effect of ZnO NPs and thiamine on the weight gain, the mice body weight was determined in the beginning treatment (day 0 ) and no significant differences were seen between the controls, untreated, and treated diabetic mice (groups I to VII) ( $p>0.05$ ). In the untreated diabetic group (group III) on days 10 and 20 body weight was significantly increased compared to the control and thiamine groups (groups I and II) and also day 0 in all groups (figure 2$)(P<0.05)$. Although, groups IV and V (diabetes $+Z n O$ NPs, 0.1 and 0.5$)$ on day 20, showed a significant increase than to controls $(P<0.05)$, but, a nonsignificant decrease was observed between groups IV and $V$ when compared to the diabetic group $(P>0.05)$. A marked reduction in body mass was observed in the ZnO NPs groups 0.1 and $0.5+$ thiamine (groups $\mathrm{VI}$ and $\mathrm{VII})$ than in the diabetic group $(P>0.05)$. Therefore, a gradual reduction was observed in the body weight in groups VI and VII (diabetes treated with ZnO NPs, 0.1 and 0.5 ) along with thiamine compared to the untreated diabetes group; near to baseline $(P>0.05)$.

\section{Volume of collagen bundles}


The volume density of collagen bundles (Table 2) in the skin samples of the untreated diabetic mice was significantly lower than those of the control and thiamine individuals $(P<0.05)$. However, twenty-day treatment with ZnO NPs ( 0.1 and 0.5 at $10 \mathrm{mg} / \mathrm{kg}$ ) and thiamine (groups 4 to 7 ) caused a significant increase in volume density of collagen when compared to the untreated diabetic group $(P<0.05)$.

\section{Morphometric criteria}

Figure 3 presents findings from the morphometrical analysis of dermis, epidermis, and hypodermis of skin in the control, untreated and treated diabetic groups. By evaluating the morphometric data, evident variations were obtained among untreated and treated diabetic groups (groups 3 to 7 ) than to control groups (groups 1 and 2), with mention to the various factors studied. Histo-morphometric criteria of the epidermis thickness exhibited a significant decrease in the untreated diabetic group (group 3) compared to the control group $(P<0.05)$. In addition, diabetes treated with ZnO NPs $(0.1$ and 0.5$)$ and thiamine showed a significant increase in epidermal thickness compared to untreated diabetic mice $(P>0.05)$, near to normal conditions.

The dermal criteria included the thickness of the dermis showed a similar histomorphometry pattern with the epidermis, as there statistically was a significant decrease in the thickness of the dermis layer in the diabetic group compared to the control group $(P<0.05)$. On the other hand, the thickness of the dermis layer displayed a sensible decrease in group 3 (diabetes alone) than in groups 4 to 7 (ZnO NPs, 0.1 and 0.5 , alone and along with thiamine) $(P>0.05)$.

The mean thickness $(\mu \mathrm{m})$ of the hypodermis layer in the diabetic and diabetic + ZnO NPs $(0.1 \mathrm{mg} / \mathrm{kg})$ groups increased significantly compared to the control group $(P<0.05)$. Treatment with ZnO NPs and thiamine showed a marked reduction in thickening hypodermis in groups 5 to 7 compared to the diabetes group (figures 2 and 3$)(P>0.05)$.

\section{Fasting blood glucose}

Table 3 summarizes the level of blood glucose (mg/dl), $\mathrm{Cr}(\mathrm{mg} / \mathrm{dl}), \mathrm{BUN}(\mathrm{mg} / \mathrm{dl})$ and GGT (u/l) of controls and experimental animals. When all the mentioned biochemical parameters were evaluated in the control group, it was found that there was no significant difference with the thiamine group $(P>0.05)$. The blood glucose level of the untreated diabetic group was significantly $(p<0.05)$ higher than the control group. Also, the concentrations of the fasting glucose in the diabetic group (351.32 \pm 4.17$)$ revealed a larger significant increase than those in the other four groups (groups 4 to 7 ), when all groups were compared with the control group $(P<0.05)$.

\section{$\mathrm{Cr}, \mathrm{BUN}$, GGT values}

A similar pattern was observed among $\mathrm{Cr}, \mathrm{BUN}$, and GGT levels when all groups in each parameter were compared. Plasma $\mathrm{Cr}, \mathrm{BUN}$, and GGT values were elevated significantly in untreated diabetic mice compared with controls $(P<0.05)$. However, the doses of 0.1 and $0.5 \mathrm{mg} / \mathrm{kg} \mathrm{ZnO} \mathrm{NPs}$ alone and along with thiamine (groups 4 to 7 ) produced a significant decrease $(P<0.05)$ in the serum levels of $\mathrm{Cr}$, $\mathrm{BUN}$, and 
GGT than to control and untreated diabetic groups. However, the biochemical experiments were not significantly changed between treated diabetic groups 4 to $7,(P>0.05)$ (Table 3$)$.

\section{MDA and NO levels}

Table 4 displayed that in the untreated diabetic mice (group 3), the MDA value was significantly higher than the control mice $(5.97 \pm 0.62$ and $3.29 \pm 0.38 \mathrm{nmol} / \mathrm{ml}$, respectively) $(P<0.05)$. Treatment with ZnO NPs $(0.1$ and $0.5 \mathrm{mg} / \mathrm{kg}$ ) alone and along with thiamine decreased the MDA value of the serum compared with the untreated diabetic mice, however, these changes were significant. $(p<0.05)$. A significant increase in the skin amount of NO was seen in the untreated diabetic mice compared with the control group $(P<0.05)$. In diabetic mice treated with ZnO NPs $(0.1$ and 0.5$)$ alone and in combination with thiamine (groups 4 to 7$)$, serum NO concentration was lower than $(0.80 \pm 0.05 \mathrm{nmol} / \mathrm{ml})$ untreated diabetic mice and higher than in the control group $(P>0.05)$.

\section{Discussion}

Cutaneous complications of diabetes have attracted a lot of attention because of the clinically remarkable problems, to the extent that it leads to a reduction in skin thickness and increased blood glucose levels $[5,24]$. From a long time ago, the balance between the disadvantages against the benefits of metal-based nanoparticles has been debated their effectiveness in counteracting the destructive effects of some diseases including diabetes, has been more pronounced. These investigations led to the fact that nanoparticles, such as zinc oxide, can show anti-hyperglycemic activity with a managed treatment for various scheduled periods [24-26]. Our study showed that alloxan-induced diabetes in mice significantly altered the skin of treated animals compared with non-diabetic animals. Diabetic mice, against non-diabetic animals, exhibit clinical symptoms of diabetes like polydipsia and polyuria (by comparing their body weight) and high fasting blood sugar $(351.32 \pm 4.17$ versus $82.33 \pm 4.10)(p<0.05)$.

A specific hallmark that facilitates molecular diagnosis in the evaluation of diabetes is the glycation formation; glycation is a non-enzymatic chemical reaction of free reducing sugars, in which reducing sugar linkage with a free amino group of proteins $[27,28]$. These irreversible reactions produce advanced glycation end products (AGEs) with the help of a chain of various reactions [27, 29]. Some AGEs that may use as a glycation stress indicator, and a marker for diabetes, included CML (Nع -(carboxymethyl) lysine) [30]. CML, a product of proteins modification by glyoxal, as a result, can be observed in high oxidative stress states and/or diabetic situations [31]. These investigations led to the fact that CML can alter skin collagen by reducing the elasticity of the skin, and shrinkage form on the skin [27].

The results of the present study showed that diabetes decreased the collagen volume density (\%) in mice skin compared to healthy mice. Besides, in groups of the ZnO NPs (0.1 and 0.5) alone and along with thiamine, the collagen volume decreased than those in the control group. Nevertheless, the effect of untreated diabetes was more severe than the effect of ZnO NPs (0.1 and 0.5) alone and along with thiamine on the collagen volume. ZnO NPs and thiamine had a controlling role in further reducing collagen volume in the diabetic group. Concerning the ZnO NPs, our results pointed out that its 
administration in combination with thiamine has more therapeutic effects than using alone. Angela et al., (2016) in the research, showed that the level of matrix metalloproteinases (MMPs) in the skin of diabetics is greatly increased [32]. Nagase et al., (2006) demonstrated MMPs are a group of proteinases, because of the nature of their substrate, contain six subclasses, including collagenase [33]. Studies that by researchers conducted over the past few years have shown that MMP-1 (collagenase) is significantly increased in naturally aged skin and or diabetes [34]. These investigations led to the conclusion that MMP-1 is the major protease capable of initiating the fragmentation of native fibrillar collagen [35].

Collagen assists the molecular constructions in developed and organized tissues, such as the skin, to maintain their morphological and mechanical properties. Since the consistency, integrity, and longevity of the dermis depend on collagen, therefore, the quality characteristics of collagen can affect these indicators [36]. Chithra et al., (1998) in their research, showed that collagen catabolism occurs in the dermis of diabetic mice, so they concluded diabetes increases collagen catabolism in skin samples. Other results of this study included thickened cutaneous artery sheaths, rupture and multilayered basement membranes with destroyed collagen fibers [37]. The present study agrees with previous research, in that the thickness per $\mu \mathrm{m}$ of the epidermis and dermis in untreated diabetic skin showed marked changes and was significantly reduced compared to the control group. In the groups of ZnO NPs (0.1 and 0.5$)$ alone and in combination with thiamine, thickness reduction was partially compensated and showed a sensible increase compared to the untreated diabetic group.

Zinc has been shown to improve glucose metabolism by increasing hepatic glycogenesis through insulin signal transductions [38]. When zinc complexes are administered orally, a tendency to lower blood glucose is also observed [39]. In the present study, intraperitoneally administration of ZnO NPs alone and along with thiamine displayed that values of serum parameters of fasting blood glucose, $\mathrm{Cr}, \mathrm{BUN}$, GGT, MDA, and NO improved compared to the untreated diabetes group. However, hyperglycemia manifested its effects by increasing $\mathrm{Cr}$, BUN, GGT, MDA, and NO levels, as a destructive agent. Some studies have been presented about the acute effects of high-dose ZnONPs on circulating blood glucose levels and have been shown that high doses of ZnONPs (e.g. $10 \mathrm{mg} / \mathrm{kg}$ ) can limit the therapeutic utilizations at diabetic patients [25]; but the anti-diabetic effects of ZnONPs have been affirmed in low doses [2, 40]. As the present study showed, the use of ZnO NPs in low doses (0.1 and 0.5) was useful as an antihyperglycemic agent and be effective in controlling the destructive effects of diabetes.

The available data about the mechanism of diabetes effect on thiamine processes are not complete and the precise mechanism is unknown; however, some research has suggested some mechanisms. Among the several enzymes involved in carbohydrate metabolism, thiamine (vitamin B1) is an essential factor that plays a vital role in carbohydrate metabolism [41]. Patrini et al., (1996) showed that diabetes causes insulin deficiency, and following, the rate of thiamine transfer among the intestine is reduced. They found that rats with insulin deficiency showed noticeably reduced transfer of free thiamine and monophosphate [42]. Inversely, when the amount of the thiamine decreases (both intake and absorption), insulin synthesis and secretion are significantly disrupted [43]. 


\section{Conclusion}

Hyperglycemia as a definitive marker in the challenge with normal conditions altered serum biochemical parameters and stereological factors in the skin. According to the stereological and biochemical findings, from one-dimension ZnO NPs and another dimension thiamine, was shown to act as anti-diabetic agents in combination together.

\section{Abbreviations}

GGT, Gamma-glutamyl Transferase; BUN, Blood Urea Nitrogen; Cr, Creatinine; MDA, Malondialdehyde; ZnO NPs, Zinc Oxide Nanoparticles; ZnO, Zinc Oxide; COA, Acetylsalicylic Acid; NADPH, Nicotinamide Adenine Dinucleotide Phosphate; IP, Intra-Peritoneal; H\&E, Hematoxylin and Eosin; TBA, Thiobarbituric Acid

\section{Declarations}

\section{Acknowledgements}

The authors respectfully thank the staff and experts of the pathophysiology and histopathology laboratories for their collaboration, as well as the research deputy of the veterinary faculty of Shahrekord University for providing the essential facilities for implementing this research study.

\section{Conflict of interests}

The authors do not declare any conflict of interest and confirm the content of this article. This research was funded by the research findings of the veterinary faculty. All the procedures are approved by the committee of animal's ethical rights of the faculty.

\section{References}

1. Mahan LK, Escott-Stump S, Gavin K III JR, Davidson MB (2004) DeFronzo RA Report of the expert committee on the diagnosis and classification of diabetes mellitus. Diabetes care 20: 1183, 1997

2. Amiri A, Fatahian Dehkordi RA, Heidarnejad MS, Dehkordi MJ (2018) Effect of the zinc oxide nanoparticles and thiamine for the management of diabetes in alloxan-induced mice: a stereological and biochemical study. Biol Trace Elem Res 181:258-264

3. Ahmadi A, Hasanzadeh J, Rahimi Madiseh M, Lashkari L (2011) Effective factors in the quality of life in patients with type 2 diabetes in Chaharmahal \& Bakhteyari Province. Journal of north Khorasan University of medical sciences 3:7-13

4. Taylor KR, Costanzo AE, Jameson JM, Suaya JA, Eisenberg DF, Fang C, Miller LG (2011) Skin and soft tissue infections and associated complications among commercially insured patients aged 064 years with and without diabetes in the US. PLoS One 8: e60057, 2013 
5. Chen X, Lin W, Lu S (2009) Insulin prevents latent skin lesions by inhibiting the generation of advanced glycation end products in streptozotocin-induced diabetic rats. Endocr Pathol 20:163

6. Cavallini M (2007) Autologous fibroblasts to treat deep and complicated leg ulcers in diabetic patients. Wound Repair Regen 15:35-38

7. Schmidt-Mende L, MacManus-Driscoll JL (2007) ZnO-nanostructures, defects, and devices. Mater Today 10:40-48

8. Odendaal J, Reinecke A (2007) Quantitative assessment of effects of zinc on the histological structure of the hepatopancreas of terrestrial isopods. Arch Environ Contam Toxicol 53:359-364

9. Juzenas P, Chen W, Sun Y, -Pet al et al (2008) Quantum dots and nanoparticles for photodynamic and radiation therapies of cancer. Adv Drug Deliv Rev 60:1600-1614

10. Rzigalinski BA, Strobl JS, Li J, Guo D, Wang X, Wang H, Jiang H, Chen B, Heinlaan M, Ivask A, Blinova I, Dubourguier H-C, Chu D, Gao J, Wang Z (2009) Neutrophil-mediated delivery of therapeutic nanoparticles across blood vessel barrier for treatment of inflammation and infection. ACS nano 9: 11800-11811, 2015

11. Siddiqui SA, Or Rashid M, Uddin M (2020) al. Biological efficacy of zinc oxide nanoparticles against diabetes: a preliminary study conducted in mice.Biosci. Rep.40,

12. Fattal I, Friedmann N, Fattal-Valevski (2011) A The crucial role of thiamine in the development of syntax and lexical retrieval: a study of infantile thiamine deficiency. Brain 134:1720-1739

13. Tunc-Ozdemir M, Miller G, Song L (2009) Thiamin confers enhanced tolerance to oxidative stress in Arabidopsis. Plant Physiol 151:421-432

14. Martin P (2001) Molecular mechanisms of thiamine utilization. Curr Mol Med 1:197-207

15. Rapala-Kozik M (2011) Vitamin B1 (Thiamine): a cofactor for enzymes involved in the main metabolic pathways and an environmental stress protectant. ed.^ ${ }^{\wedge}$ eds. Advances in botanical research. Elsevier, ; 37-91

16. Bâ A (2008) Metabolic and structural role of thiamine in nervous tissues. Cell Mol Neurobiol 28:923

17. Rodríguez JL, Qizilbash N, López-Arrieta J (2001) Thiamine for Alzheimer's disease. Cochrane Database of Systematic Reviews: CD001498,

18. Dehkordi RAF, Moradi H (2015) Stereological estimation and morphological assessment of the endocrine pancreatic components in relation to sex in hen. ed. ${ }^{\wedge}$, eds. Veterinary Research Forum. Faculty of Veterinary Medicine. Urmia University, Urmia, Iran, p 49

19. Inuwa IM (2005) First-order stereology in diabetes and endocrine research-number and volume estimation of objects. INTERNATIONAL JOURNAL OF DIABETES AND METABOLISM 13:10

20. Ayala A, Muñoz MF, Argüelles S (2014) Lipid peroxidation: production, metabolism, and signaling mechanisms of malondialdehyde and 4-hydroxy-2-nonenal. Oxid. Med. Cell. Longev. 2014

21. Yazdi HB, Hojati V, Shiravi A, Hosseinian S, Vaezi G, Hadjzadeh M-A-R (2019) Liver dysfunction and oxidative stress in streptozotocin-induced diabetic rats: protective role of Artemisia turanica. Journal of pharmacopuncture 22:109 
22. Kalugalage T, Rodrigo C, Vithanage T (2013) Low serum total nitrite and nitrate levels in severe leptospirosis. BMC Infect Dis 13:1-8

23. Syal K, Srinivasan A, Banerjee D (2013) Streptomycin interference in Jaffe reaction-possible false positive creatinine estimation in excessive dose exposure. Clin Biochem 46:177-179

24. Ahmed F, Husain Q, Ansari MO, Shadab G (2020) Antidiabetic and oxidative stress assessment of bio-enzymatically synthesized zinc oxide nanoformulation on streptozotocin-induced hyperglycemic mice. Applied Nanoscience 10:879-893

25. Virgen-Ortiz A, Apolinar-Iribe A, Díaz-Reval I Zinc Oxide Nanoparticles Induce an Adverse Effect on Blood Glucose Levels Depending On the Dose and Route of Administration in Healthy and Diabetic Rats. Nanomaterials 10 et al (2005) : 2020

26. Prabhu S, Vinodhini S, Elanchezhiyan C, Rajeswari D, Bayrami A, Parvinroo S, Habibi-Yangjeh A, ElGharbawy RM, Emara AM (vol 10, pg 28, 2018) Abu-Risha SE-S Zinc oxide nanoparticles and a standard antidiabetic drug restore the function and structure of beta cells in Type-2 diabetes. Biomed. Pharmacother. 84: 810-820, 2016; Nazarizadeh A, Asri-Rezaie S Comparative study of antidiabetic activity and oxidative stress induced by zinc oxide nanoparticles and zinc sulfate in diabetic rats. AAPS PharmSciTech 17: 834-843, 2016

27. Ichihashi M, Yagi M, Nomoto K, Yonei Y (2011) Glycation stress and photo-aging in skin. Anti-Aging Medicine 8:23-29

28. Kim C-S, Park S, Kim J (2017) The role of glycation in the pathogenesis of aging and its prevention through herbal products and physical exercise. J Exerc Nutr Biochem 21:55

29. Hafizur RM, Momin S, Fatima N (2017) Prevention of advanced glycation end-products formation in diabetic rats through beta-cell modulation by Aegle marmelos. BMC Complement Altern Med 17:115

30. Jara N, Leal M, Bunout D, Mizutari K, Ono T, Ikeda K (2012) Kayashima K-i, Horiuchi S PhotoEnhanced Modification of Human Skin Elastin in Actinic Elastosis by $\mathrm{N} \in$-(Carboxymethyl) lysine, One of the Glycoxidation Products of the Maillard Reaction. Journal of investigative dermatology 108: 797-802, 1997

31. Kawaguchi M, Shibata N, Horiuchi S, Kobayashi M (2005) Glyoxal inactivates glutamate transporter1 in cultured rat astrocytes. Neuropathology 25:27-36

32. Argyropoulos AJ, Robichaud P, Balimunkwe RMet (2016) Alterations of dermal connective tissue collagen in diabetes: molecular basis of aged-appearing skin. PLoS ONE 11:e0153806

33. Nagase H, Visse R, Murphy G (2006) Structure and function of matrix metalloproteinases and TIMPs. Cardiovasc Res 69:562-573

34. Brenneisen P, Sies H, Scharffetter-Kochanek (2002) K Ultraviolet-B irradiation and matrix metalloproteinases: from induction via signaling to initial events. Ann N Y Acad Sci 973:31-43

35. Brennan M, Bhatti H, Nerusu KCet (2003) Matrix metalloproteinase-1 is the major collagenolytic enzyme responsible for collagen damage in UV-irradiated human skin 9 . Photochem Photobiol 78:43-48 
36. Akarca S, Yavaşoğlu A, Ayşegül U (2012) Investigation on the effects of experimental STZ-induced diabetic rat model on basal membrane structures and gap junctions of skin. International Journal of Diabetes in Developing Countries 32:82-89

37. Chithra P, Sajithlal G, Chandrakasan G (1998) Influence of Aloe vera on collagen characteristics in healing dermal wounds in rats. Mol Cell Biochem 181:71-76

38. Jansen J, Karges W, Rink L (2009) Zinc and diabetes-clinical links and molecular mechanisms. J Nutr Biochem 20:399-417

39. Yoshikawa Y, Adachi Y, Yasui H, Hattori M, Sakurai H, Ueda E, Yoshikawa Y, Sakurai H, Kojima Y (2011) Kajiwara NM In vitro alpha-glucosidase inhibitory effect of Zn (II) complex with 6-methyl-2picolinmethylamide. Chem. Pharm. Bull. (Tokyo) 53: 451-452, 2005

40. Alkaladi A, Abdelazim AM, Afifi M, da Silva BL, Abuçafy MP (2014) Manaia EB Relationship between structure and antimicrobial activity of zinc oxide nanoparticles: An overview. International journal of nanomedicine 14: 9395, 2019

41. Page G, Laight $D$, Cummings $M$ (2011) Thiamine deficiency in diabetes mellitus and the impact of thiamine replacement on glucose metabolism and vascular disease. Int J Clin Pract 65:684-690

42. Patrini $C$ (1996) Effects of insulin on thiamine intestinal transport in rat everted jejunal sacs. $J$ Physiol (Lond) 493:100-101

43. Mee L, Nabokina SM, Sekar VT, Subramanian VS, Maedler K, Said HM Pancreatic beta cells and islets take up thiamin by a regulated carrier-mediated process: studies using mice and human pancreatic preparations.American Journal of Physiology-Gastrointestinal and Liver Physiology297: G197-G206, 2009.

\section{Tables}

Table 1: The principal physical characteristics of the ZnO NPs (production reported)

\begin{tabular}{|ll|}
\hline ASP & $10-30 \mathrm{~nm}$ \\
\hline Crystal phase & Single crystal \\
\hline Color & White \\
\hline Morphology & Nearly spherical \\
\hline True density & $5.606 \mathrm{~g} / \mathrm{cm}^{3}$ \\
\hline SSA & $20-60 \mathrm{~m}^{2} / \mathrm{g}$ \\
\hline
\end{tabular}

*Table 2: Quantitative parameter of volume density of collagen bundles $\left(\mathrm{V}_{\mathrm{v}} ; \%\right),($ Mean $\pm S D)$ 


\begin{tabular}{|c|c|c|c|}
\hline \multicolumn{2}{|c|}{ groups } & \multirow{2}{*}{$\begin{array}{l}\text { Collagen Volume Density, \% } \\
37.5^{\mathrm{a}}\end{array}$} & \multirow{2}{*}{$\begin{array}{l}\text { P Value } \\
-\end{array}$} \\
\hline gl & Control & & \\
\hline g II & Thiamine & $36.8^{a}$ & - \\
\hline g III & Diabetes & $33.5^{b}$ & $P<0.05$ \\
\hline g IV & $\mathrm{D}+\mathrm{ZnO}$ NPs $(0.1 \mathrm{mg} / \mathrm{kg})$ & $36.4^{\mathrm{a}}$ & $p>0.05$ \\
\hline$g \vee$ & $\mathrm{D}+\mathrm{ZnO} \mathrm{NPs}(0.5 \mathrm{mg} / \mathrm{kg})$ & $36.2^{\mathrm{a}}$ & $p>0.05$ \\
\hline $\mathrm{g} \mathrm{VI}$ & $\mathrm{D}+\mathrm{ZnO}$ NPs $(0.1 \mathrm{mg} / \mathrm{kg})+$ Thiamine & $35.9^{a}$ & $p>0.05$ \\
\hline g VII & $\mathrm{D}+\mathrm{ZnO}$ NPs $(0.5 \mathrm{mg} / \mathrm{kg})+$ Thiamine & $36.2^{a}$ & $p>0.05$ \\
\hline
\end{tabular}

a - b Means in the same column with different letters are significantly different $(P<0.05) ;{ }^{*}$ The table above shows the values measured 20 days after diabetes induction on mice; $D=$ Diabetes.

*Table 3: The amounts of blood factors (means $\pm S D$ ) in all the groups during the study period

\begin{tabular}{|c|c|c|c|c|c|}
\hline \multicolumn{2}{|c|}{ Groups } & \multirow{2}{*}{$\begin{array}{l}\begin{array}{l}\text { Glucose } \\
(\mathrm{mg} / \mathrm{dl})\end{array} \\
82.33 \pm 4.10^{\mathrm{a}}\end{array}$} & \multirow{2}{*}{$\begin{array}{l}\mathrm{Cr} \\
(\mathrm{mg} / \mathrm{dl}) \\
0.23 \pm 0.02 \\
\mathrm{a}\end{array}$} & \multirow{2}{*}{$\begin{array}{l}\text { BUN } \\
(\mathrm{mg} / \mathrm{dl}) \\
43.83 \pm 5.89^{\mathrm{a}}\end{array}$} & \multirow{2}{*}{$\begin{array}{l}\text { GGT } \\
(\mathrm{U} / \mathrm{L}) \\
6.31 \pm 0.65^{\circ}\end{array}$} \\
\hline gl & Control & & & & \\
\hline g II & Thiamine & $80.80 \pm 3.61^{a}$ & $\begin{array}{l}0.21 \pm 0.03 \\
\mathrm{a}\end{array}$ & $44.40 \pm 5.47^{a}$ & $6.42 \pm 0.57^{\circ}$ \\
\hline g III & Diabetes & $351.32 \pm 4.17^{b}$ & $\begin{array}{l}0.89 \pm 0.12 \\
b\end{array}$ & $86.74 \pm 7.10^{b}$ & $\begin{array}{l}12.15 \pm 1.56 \\
b\end{array}$ \\
\hline$\stackrel{g}{\mathrm{IV}}$ & $\begin{array}{c}\mathrm{D}+\mathrm{ZnO} \text { NPs } \\
(0.1 \mathrm{mg} / \mathrm{kg})\end{array}$ & $150.87 \pm 5.51^{c}$ & $\begin{array}{l}0.52 \pm 0.02 \\
c\end{array}$ & $63.62 \pm 5.82^{c}$ & $9.91 \pm 1.09$ \\
\hline$g \vee$ & $\begin{array}{c}D+Z n O ~ N P s \\
(0.5 \mathrm{mg} / \mathrm{kg})\end{array}$ & $162.66 \pm 3.67^{c}$ & $\begin{array}{l}0.47 \pm 0.03 \\
c\end{array}$ & $67.50 \pm 6.93^{c}$ & $8.89 \pm 0.91$ \\
\hline$\stackrel{g}{\mathrm{Vl}}$ & $\begin{array}{l}\mathrm{D}+\mathrm{ZnO} N P s(0.1 \mathrm{mg} / \mathrm{kg})+ \\
\text { Thiamine }\end{array}$ & $123.16 \pm 7.38^{c}$ & $\begin{array}{l}0.36 \pm 0.02 \\
c\end{array}$ & $55.23 \pm 5.36^{c}$ & $8.06 \pm 0.87$ \\
\hline $\begin{array}{l}\mathrm{g} \\
\text { VII }\end{array}$ & $\begin{array}{l}\mathrm{D}+\mathrm{ZnO} \mathrm{nPs}(0.5 \mathrm{mg} / \mathrm{kg})+ \\
\text { Thiamine }\end{array}$ & $114.2 \pm 4.63^{c}$ & $\begin{array}{l}0.32 \pm 0.02 \\
c\end{array}$ & $54.42 \pm 5.34^{c}$ & $7.57 \pm 0.86^{c}$ \\
\hline
\end{tabular}

${ }^{a-c}$ Means in the same column with different letters are significantly different $(P<0.05) ;{ }^{*}$ The above table shows values measured 20 days after induction of diabetes in mice; D: diabetes. 
*Table 4: The concentrations of MDA and NO in all the groups (means \pm SD)

\begin{tabular}{|lllll|}
\hline groups & MDA $(\mathrm{nmol} / \mathrm{ml})$ & NO $(\mu \mathrm{mol} / \mathrm{ml})$ & $P$ Value \\
\hline $\mathrm{g} \mathrm{I}$ & Control & $3.29 \pm 0.38^{\mathrm{a}}$ & $0.21 \pm 0.04^{\mathrm{a}}$ & - \\
\hline $\mathrm{g} \mathrm{II}$ & Thiamine & $3.31 \pm 0.47^{\mathrm{a}}$ & $0.22 \pm 0.03^{\mathrm{a}}$ & - \\
\hline $\mathrm{g}$ III & Diabetes & $5.97 \pm 0.62^{\mathrm{b}}$ & $0.80 \pm 0.05^{\mathrm{b}}$ & $p<0.05$ \\
\hline $\mathrm{g} \mathrm{IV}$ & $\mathrm{D}+\mathrm{ZnO} \mathrm{NPs}(0.1 \mathrm{mg} / \mathrm{kg})$ & $4.86 \pm 0.44^{\mathrm{a}}$ & $0.45 \pm 0.04^{\mathrm{a}}$ & $p>0.05$ \\
\hline $\mathrm{g} \mathrm{V}$ & $\mathrm{D}+$ ZnO NPs $(0.5 \mathrm{mg} / \mathrm{kg})$ & $4.72 \pm 0.35^{\mathrm{a}}$ & $0.42 \pm 0.03^{\mathrm{a}}$ & $p>0.05$ \\
\hline $\mathrm{g} \mathrm{VI}$ & $\mathrm{D}+\mathrm{ZnO} \mathrm{NPs}(0.1 \mathrm{mg} / \mathrm{kg})+$ Thiamine & $4.01 \pm 0.33^{\mathrm{a}}$ & $0.40 \pm 0.05^{\mathrm{a}}$ & $p>0.05$ \\
\hline $\mathrm{g} \mathrm{VII}$ & $\mathrm{D}+\mathrm{ZnO} \mathrm{NPs}(0.5 \mathrm{mg} / \mathrm{kg})+$ Thiamine & $3.85 \pm 0.32^{\mathrm{a}}$ & $0.38 \pm 0.04^{\mathrm{a}}$ & $p>0.05$ \\
\hline
\end{tabular}

a-b Means in the same column with different letters are significantly different $(P<0.05) ;{ }^{*}$ The table above shows the values measured 20 days after diabetes induction on mice; $D=$ Diabetes.

Figures 


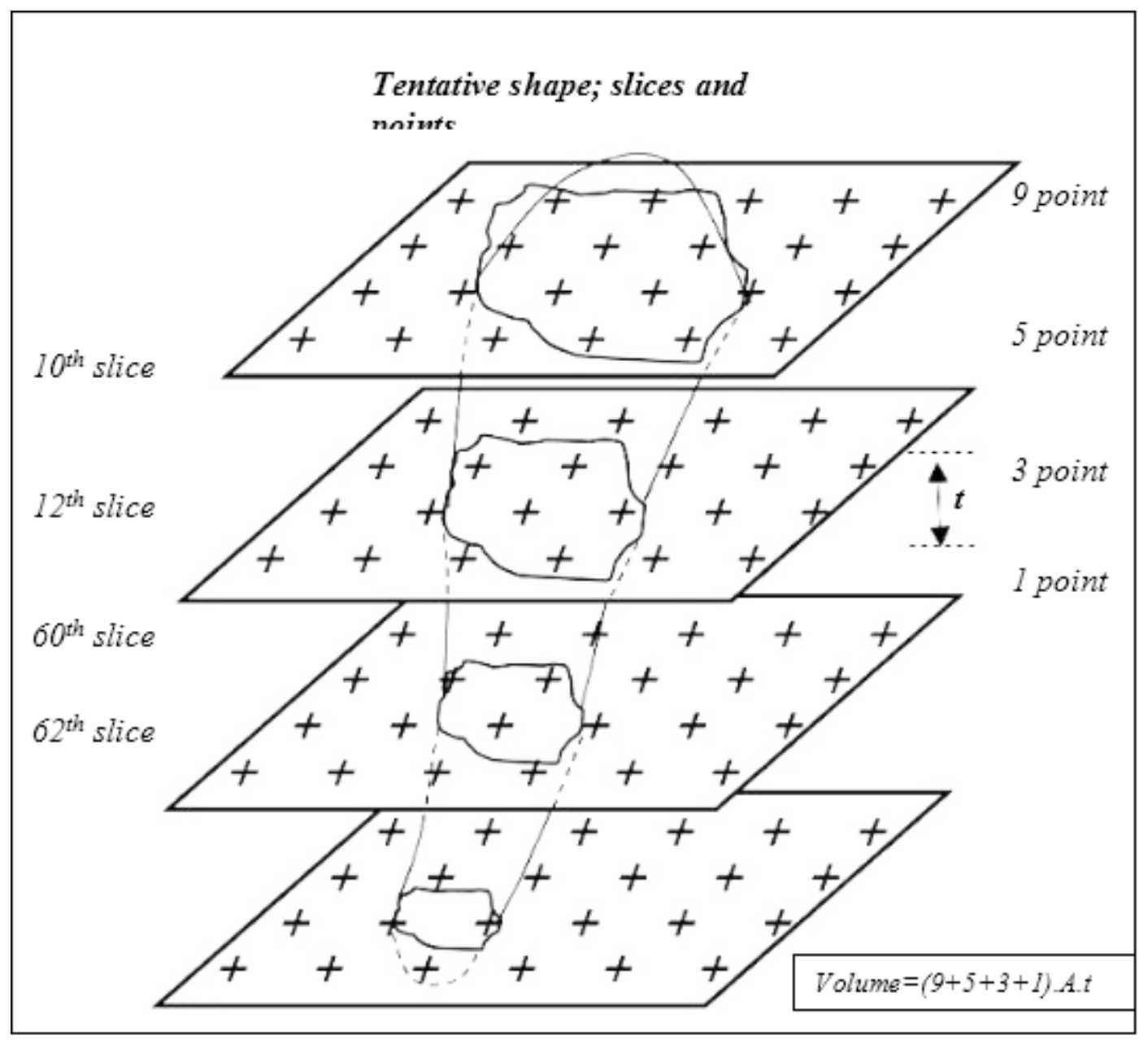

Figure 1

Illustration of the sample scheme of skin tissue sections. Systematic random samples from skin slices superimposed by a grid of the point square to obtain volume of uniform random samples. Samples were prepared by a series of parallel cutting plates (serially sections) with slice thickness t distance. The number of serial sections on which the point grid is superimposed, includes four slices. 


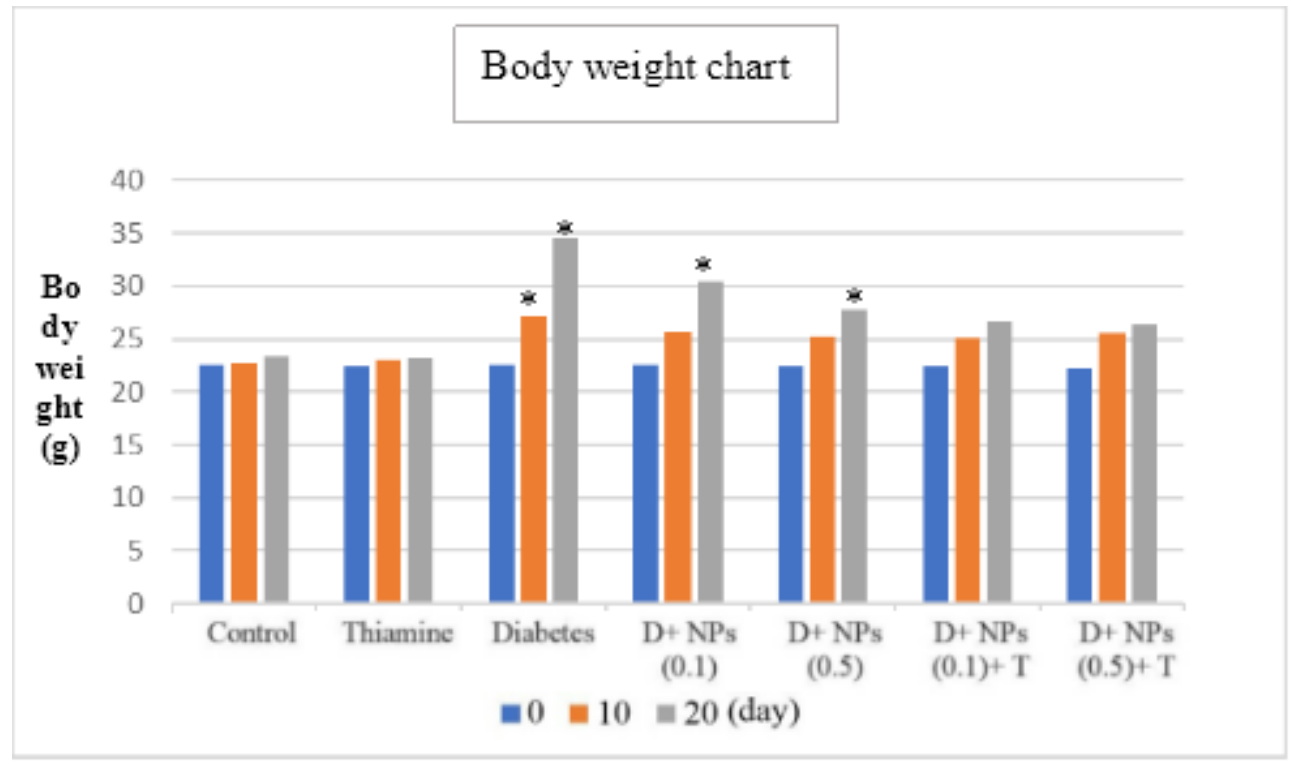

\section{Figure 2}

The mean changes from $\mathrm{d}$ ay 0 in body weight $(\mathrm{g})$, for all controls plus diabetes (untreated and treated); D: Diabetes; T: Thiamine, NPs: ZnO nanoparticles; mean \pm SD $(n=7)$; *significant difference in each group with day 0 and control, $p<0.05$.

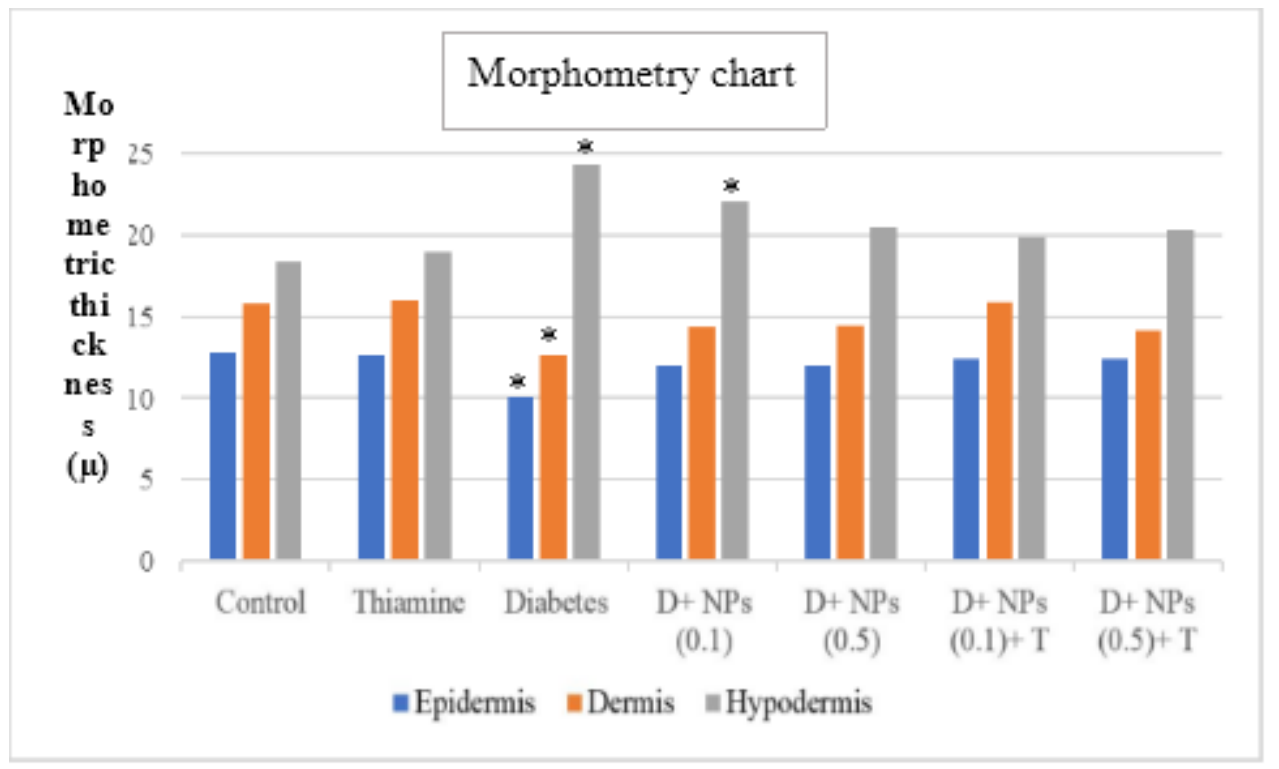

\section{Figure 3}

The morphometrical parameters of measured in different layers of cutaneous tissue in experimental groups; mean $\pm S D(n=7)$; * significant difference in each parameter with the control group; $p<0.05$. 